\title{
Vidas entre livros: Plínio Doyle e José Mindlin
}

\section{Lives among books: Plínio Doyle and José Mindlin}

https://doi.org/10.34112/2317-0972a2016v34n66p143-151

\section{CÁssia dos Santos ${ }^{1}$}

RESUMO: Tendo dedicado suas existências à preservação do livro e à valorização da leitura, Plínio Doyle (1906-200o) e José Mindlin (1914-2010) foram mais do que bibliófilos. Donos de uma largueza de espírito e de uma generosidade inata, os dois autores contribuíram decisivamente para a vida literária e cultural do País com diversas iniciativas ao longo das décadas. Parte delas é apresentada neste texto, que se ocupa, ainda, da visão de cada um deles sobre sua própria trajetória. Para tanto, considera-se a leitura de Uma vida, livro de memórias de Doyle, publicado em 1999, e de Uma vida entre livros: reencontros com o tempo, de José Mindlin, lançado no ano de 1997.

Palavras-chave: Plínio Doyle (1906-200o); José Mindlin (1914-2010); bibliófilos; vida cultural. ${ }^{2}$

ABStRACT: Having dedicated their lives to book preserving and reading appreciation, Plinio Doyle (1906-2000) and José Mindlin (1914-2010) were more than bibliophiles. Proving broad-mindedness and innate generosity, both of them definitely contributed to the country's literary and cultural life with a variety of initiatives throughout the decades. Part of which is presented in this text that still relates the point of view of each of them about their own course.

1. Pontifícia Universidade Católica de Campinas, Campinas, SP, Brasil.

2. Uma versão preliminar deste texto foi apresentada no $19^{\circ}$ Congresso de Leitura do Brasil, sob o título "Duas vidas dedicadas ao livro e à leitura: Plínio Doyle e José Mindlin”, sem que tenha havido publicação nos Anais. 
In order to achieve so, one considers the reading of One life (Uma vida), a book of memories, published by Doyle in 1999, and A life among books: reencounters with time (Uma vida entre livros: reencontros com o tempo) by José Mindlin, launched in the year 1997.

KEYwORDS: Plínio Doyle (1906-200o); José Mindlin (1914-2010); bibliophiles; cultural life.

Amigos diletos, Plínio Doyle e José Mindlin trilharam caminhos afins no amor pelo livro e pela leitura. Outras semelhanças marcaram suas trajetórias, que se aproximaram pelas importantes contribuições que ambos deram à vida literária e cultural do País.

Oito anos mais velho que Mindlin, Doyle nasceu no Rio de Janeiro em 1906 e estudou na Faculdade de Direito, situada à época em um velho prédio da Rua do Catete. Como advogado, atuou em áreas diversas, com exceção da criminal, tendo trabalhado inclusive para a editora José Olympio entre 1935 e 1960. Foi, ainda, procurador da Fazenda Nacional, cargo no qual se aposentou no ano de 1976. Em sua existência longeva, sempre permaneceu perto dos livros e dos escritores, como revela no livro de memórias que redigiu, por insistência de velhos amigos, às vésperas de completar 90 anos.

Em Uma vida, publicado no Rio de Janeiro em 1999, Doyle relembra fatos de sua vida pessoal e profissional, contando como despertou seu amor pelos livros e como se formou sua extraordinária biblioteca, composta de cerca de 25.00o volumes que hoje se encontram depositados na Fundação Casa de Rui Barbosa. As obras mais raras que conseguiu adquirir, as circunstâncias que fizeram chegar às suas mãos os originais dos romances Til, de José de Alencar, e Canaã, de Graça Aranha, os amigos livreiros que conquistou em suas persistentes buscas nos sebos e nas livrarias, as relações que travou com escritores - tudo isso, enfim, e muito mais, é objeto da atenção do memorialista em sua prosa enxuta e de leitura agradável.

A série de dedicatórias que escolheu transcrever comprova o apreço e a admiração que autores famosos, como Manuel Bandeira, Carlos Drummond de Andrade e Guimarães Rosa, tiveram por ele. Escolhido por Rosa para guardar um dos dois exemplares de cada um de seus livros em versão traduzida que costumava receber dos editores do exterior, ouviu: "Você está proibido de comprar qualquer tradução minha; os editores estrangeiros me mandam apenas dois exemplares e eu vou dar um a você e fico com outro, que vou perder, e fica o seu" (DOYLE, 1999, p. 72).

Percorrer as páginas dessas memórias permite concluir que Doyle nunca perdeu a oportunidade de cuidar dos livros e de auxiliar generosamente seus admiradores. 
Eleito bibliotecário do Instituto dos Advogados Brasileiros na década de 1940, organizou o acervo da biblioteca, arrumando, com a ajuda de dois boys de seu escritório, o conjunto de mais de 10.000 volumes, aos sábados pela manhã. Foi, contudo, somente depois de haver se aposentado que pôde devotar-se em tempo integral "à cultura e à literatura, na medida de minhas forças e com o entusiasmo que nunca me abandonou", explica Doyle (1999, p. 124). Inicialmente, organizou a Associação Profissional dos Escritores do Estado da Guanabara, atual estado do Rio de Janeiro, e participou da criação do Sindicato dos Escritores. Entre abril de 1979 e janeiro de 1982, foi diretor da Biblioteca Nacional, que administrou com competência e seriedade, mas também com satisfação e alegria, por conseguir pôr em dia as publicações pendentes da instituição. Doyle foi membro, ainda, do Conselho Federal de Cultura, sócio titular do Instituto Histórico e Geográfico Brasileiro e sócio correspondente de várias instituições estrangeiras. A pedido de Austregésilo de Athayde, elaborou um vasto plano de reforma e de organização da biblioteca da Academia Brasileira de Letras, que, por falta de verbas, não chegou a ser executado.

A sua mais relevante contribuição às letras brasileiras talvez tenha sido, não obstante tudo o que foi mencionado, a criação do Arquivo-Museu de Literatura Brasileira, entidade subordinada à Fundação Casa de Rui Barbosa e que concentra até o momento textos e documentos referentes a 129 autores brasileiros. A ideia para a criação do órgão é filha dileta de outra das iniciativas de Doyle, que merece ser destacada antes de que se trate do museu.

Em 1957, tendo reunido e mandado encadernar certo número de crônicas produzidas por Carlos Drummond de Andrade e divulgadas no jornal Correio da Manhã, Doyle deixou o volume com os textos na mesa do editor José Olympio, onde foi visto pelo poeta. Disso resultou o início de uma amizade, pois Drummond escreveu e publicou no jornal o poema "Saudação", em agradecimento à atitude do bibliófilo, e ambos, a partir de então, tornaram-se próximos. Anos mais tarde, em fins de 1964, Drummond passou a visitar o amigo aos sábados para conversarem e para consultar os livros de sua biblioteca, onde buscava elementos para a composição das crônicas. Aos poucos, outros autores passaram a comparecer às mesmas visitas e, embora Doyle não se recorde de todos os nomes presentes no início, sabe que Américo Lacombe, Joaquim Inojosa, Aurélio Buarque de Holanda, Ciro dos Anjos e Peregrino Júnior se encontravam entre eles.

O número de participantes das reuniões foi paulatinamente crescendo. Também o acervo da biblioteca crescia cada vez mais, o que obrigou seu proprietário, em 
1972, a comprar um apartamento, quase ao lado de sua residência, somente para abrigar os livros e receber os amigos. Doyle revela que, nesse mesmo ano, alguém pensou em criar uma ata semanal, que registrasse os acontecimentos das reuniões, e para tanto providenciou um volume especialmente encadernado. Esclarece também que, se bem que já acontecessem há quase oito anos, as reuniões não haviam sido batizadas, o que ocorreu em 6 de abril de 1974, quando o escritor Raul Bopp, responsável pela redação da ata do dia, cunhou o neologismo "Sabadoyle" para designá-las.

Contando com grande número de intelectuais, ficcionistas e poetas, residentes no Rio de Janeiro ou de passagem pela capital carioca, os sabadoyles perduraram por 34 anos como um espaço em que discussões sobre política e religião eram vetadas. Somente os livros, as ações e as iniciativas dos autores deviam receber atenção, e assim foi até 26 de dezembro de 1998, data em que Doyle, enfermo e idoso, decidiu pôr fim às tertúlias. Delas, no entanto, muito foi preservado: Homero Senna, um dos integrantes do grupo, escreveu um livro de leitura saborosíssima que, publicado em 1985, ganhou sua segunda edição em 2000 com o título de O Sabadoyle: histórias de uma confraria literária. Na obra, que recupera fatos significativos e episódios pitorescos ocorridos durante as reuniões, Senna conta como nasceram o Sabadoyle e o sabadoylismo, como as atas passaram a ser escritas em verso ou prosa por um dos participantes do dia e como as mais importantes foram veiculadas depois em livro.

De tudo o que nos legou o Sabadoyle, entretanto, o que ficou de mais notável foi o Arquivo-Museu de Literatura Brasileira, criado por sugestão de Carlos Drummond de Andrade, mas viabilizado pelos esforços incansáveis de Doyle. Fundado em 28 de dezembro de 1972 e instalado numa das salas do terceiro andar da Casa de Rui Barbosa, o Arquivo transferiu-se depois para espaço próprio em prédio anexo e foi dirigido pelo bibliófilo de 1972 a 199o. Com o auxílio de uma equipe competente, Plínio Doyle construiu os alicerces do órgão que preserva hoje os arquivos de escritores importantes de nossa literatura, como Manuel Bandeira, Clarice Lispector, Carlos Drummond de Andrade, Vinícius de Morais, Pedro Nava, Rubem Braga, Lúcio Cardoso e muitos outros. Além de conservar originais, correspondência e documentos de mais de uma centena de autores, o Arquivo-Museu organiza e publica inventários dos arquivos recebidos, promove exposições e permite a consulta do rico material que tem sob sua guarda, desde que respeitadas algumas condições.

Narradas com modéstia por Doyle ao longo de Uma vida, todas as ações citadas dão provas de seu caráter generoso, do espírito perspicaz e entusiasmado, demonstrando o quanto a cultura e, sobretudo, a literatura brasileira devem a ele. Não menor 
é a dívida que têm para com José Mindlin, o segundo bibliófilo de que trata este artigo, espécie de alma gêmea de Doyle no amor pelos livros e pelas bibliotecas.

Nascido em São Paulo em 1914, filho de pais russos, Mindlin cursou Direito na Faculdade do Largo de São Francisco, abraçando a mesma carreira que o amigo carioca. Assim como esse, já idoso, escreveu por incentivo de Antonio Candido um livro de memórias em que reconstitui as linhas gerais de sua vida e a sua longa relação com os livros. Na esfera profissional, Mindlin recorda como, ainda antes de ingressar na faculdade, iniciou seu trabalho como repórter e redator no jornal O Estado de S. Paulo, função que se viu obrigado a abandonar em 1934, devido ao estágio necessário para a conclusão do curso. Trata, também, do exercício da advocacia, do aprendizado que esse representou ao longo de 15 anos e, por fim, de como se tornou empresário, ao se juntar a clientes seus que desejavam fundar uma fábrica de pistões, a Metal Leve. Embora seu propósito não seja se ocupar da história da fábrica, julga importante mencioná-la não apenas "pelo papel cultural, além de industrial, que a Metal Leve veio a exercer” (MINDLIN, 1997, p. 79), como também para evidenciar que interesses intelectuais não são incompatíveis com a atividade empresarial.

O bibliófilo ainda se refere a cargos e funções que desempenhou em vários órgãos e entidades relacionados à cultura, à ciência e à tecnologia, tendo participado também de organizações de interesse social, como museus e bibliotecas públicas. Com brevidade, como se não desejasse chamar a atenção para o fato, esclarece que fez parte dos Conselhos da Fapesp, do CNPq e do IPHAN (Instituto do Patrimônio Histórico e Artístico Nacional), do Conselho Curador da Fundação Getúlio Vargas e de outros assemelhados, tendo se ligado ainda à Fundação Vitae e ao Museu de Arte Moderna de Nova York. Mindlin relembra o convite que recebeu em 1975 do então governador de São Paulo, Paulo Egydio, para assumir a Secretaria da Cultura, Ciência e Tecnologia, explicando que decidiu aceitá-lo depois de ouvir de Antonio Candido que, "se quem queria a abertura o recusasse, ele seria ocupado por quem não a desejava. E acrescentou que não tinha dúvida em dar esse conselho, por ter a certeza de que, se as coisas não dessem certo, eu pediria demissão" (MINDLIN, 1997, p. 84). De fato, foi o que aconteceu, como revela no capítulo em que relata as lições da experiência no setor público. Apontando as dificuldades que encontrou durante a permanência no cargo, descreve sucintamente ações e projetos que idealizou e executou, apresentando os frutos colhidos do seu trabalho e os motivos que o levaram a pedir demissão depois da morte do jornalista Wladimir Herzog, nomeado por ele como diretor de jornalismo da Fundação Padre Anchieta. 
Mais interessado em mostrar como se deu a formação de sua incrível biblioteca e em recuperar episódios de perseguição a livros raros e outros de contato com os escritores, Mindlin não enumera todos os cargos e tarefas que desempenhou, apesar de não se furtar a citar vários deles. Assim, somente com a leitura de sua biografia disponível no site da Academia Brasileira de Letras, para a qual foi eleito em 2006, e com a consulta aos dados existentes na página sobre ele e a esposa no site da Biblioteca Brasiliana Guita e José Mindlin, é que se tem a noção completa de tudo que fez e empreendeu.

No livro, Mindlin destaca outras iniciativas em que esteve igualmente envolvido, como a fundação de uma livraria que manteve em parceria com o amigo Claude Blum entre 1946 e 1951 e que vendeu, quando verificou que "ter uma biblioteca e uma livraria são coisas que não combinam” (MINDLIN, 1997, p. 124). Cita todos os livros e revistas que ajudou a editar, seja por conta própria, seja com o patrocínio da Metal Leve. Em tom de conversa, rememora como se iniciou seu amor pela leitura, o primeiro livro raro que comprou, aos 13 anos de idade, os episódios de garimpagem em sebos e livrarias no Brasil e no exterior, as aquisições mais preciosas. Reconhecendo ser impossível tratar de todos os livros raros existentes em sua grande biblioteca (oito ou dez mil seriam raros, ou pouco comuns e, desses, um ou dois mil seriam muito raros, segundo ele), limita-se a assinalar os que lhe parecem mais importantes, como incunábulos, manuscritos antigos, livros dos séculos XVI e XVII e outros. Inclui entre esses, por exemplo, as duas edições de Os Lusíadas, publicadas em 1572, e uma edição das Poesias completas, de Machado de Assis, lançada pela Garnier em 1907, com um erro cometido pelo tipógrafo e corrigido à mão pelo próprio Machado. ${ }^{3}$ Ênfase especial é conferida ao relato da formação de uma das vertentes da biblioteca, a chamada Brasiliana, que reúne livros de "literatura (prosa e poesia), história, relatos de viagens, crítica literária e ensaios em geral, filologia, obras de missionários, almanaques, revistas,

3. Ressaltando que há muitas razões que fazem de um livro comum uma grande raridade, Mindlin conta que Machado incluiu uma "Advertência" nas páginas iniciais das Poesias completas, afirmando que "não tinha deixado o prefácio de Caetano Filgueiras porque 'a afeição do meu defunto amigo a tal extremo lhe cegara o juízo que não viria a ponto reproduzir aqui aquela saudação inicial'. Acontece que no 'cegara' em lugar de um 'e' saiu um 'a'! O erro foi detectado logo, Machado corrigiu à mão os exemplares que já tinham sido impressos e, daí por diante, a impressão saiu corrigida. Mas assim mesmo uns poucos exemplares escaparam da correção. Não sei, aliás, como é que Machado não teve um ataque de apoplexia... Na biblioteca estão os três exemplares: com o erro, com ele corrigido à mão, e sem erro.” (MINDLIN, 1997, p. 29). 
e até mesmo, embora em escala limitada, medicina, história natural, botânica e zoologia” (MINDLIN, 1997, p. 135).

Se a leitura de Uma vida entre livros já é muito interessante por si só, as ilustrações presentes no livro de memórias o enriquecem sobremaneira, pois muitas das obras e revistas aludidas no texto têm sua capa ou folha de rosto reproduzidas. Mindlin, porém, a despeito do imenso significado de sua biblioteca, não se considera seu proprietário, afirmando a uma dada altura que "a biblioteca é que os tem", a ele e a Guita, sua esposa e grande incentivadora, responsável também pelo restauro de muitos dos exemplares lá depositados.

Observa, portanto, na conclusão da obra que, em relação aos livros, não tem

o fetiche da propriedade. Sinto-me mais como um depositário do que um proprietário, usufruindo, é verdade, o prazer que eles proporcionam, mas visando preservar uma herança do passado, e conservar o que se faz de bom agora, com o propósito de transmitir tudo isso para o futuro. Tenho procurado desenvolver uma atividade cultural em várias frentes, promover edições de obras úteis e reedição de outras esgotadas que considero importantes. Desenvolver, em suma, um trabalho que é uma das razões de ser na vida. (MINDLIN, 1997, p. 213-214).

Em coerência com tais palavras, ele, a esposa e os filhos decidiram doar, em um gesto de extrema generosidade, o acervo extraordinário à Universidade de São Paulo. A cerimônia de doação ocorreu em maio de 2006 e, em março de 2013, foi inaugurada a sede da Biblioteca Brasiliana Guita e José Mindlin, que comporta os 32,2 mil títulos, correspondentes a 60 mil volumes aproximadamente. Em respeito aos ideais defendidos pelo bibliófilo, que sempre pretendeu fazer dela "uma biblioteca viva”, deverá expandir seu acervo com o passar do tempo, incorporando novos títulos que dialoguem com suas vertentes. No texto existente na página digital da instituição, lê-se, conforme seu regimento, que "tem o compromisso de conservar, divulgar e facilitar o acesso de estudantes, pesquisadores e do público em geral ao acervo, e promover a disseminação de estudos de assuntos brasileiros por meio de programas e projetos específicos".

José Mindlin não viveu tempo suficiente para ver a biblioteca instalada em sua nova casa, diferentemente de Plínio Doyle, que teve a satisfação de ver seus 25.00o livros organizados na biblioteca da Fundação Casa de Rui Barbosa e disponíveis para consulta de pesquisadores e outros estudiosos. Esse pôde, também, 
acompanhar com alegria a publicação do Catálogo dos periódicos da coleção Plínio Doyle, no ano de 1998, apresentando os 1.730 títulos que reuniu em anos e anos de dedicação. Afirma ele em Uma vida que "a paciência do colecionador não pode ter limites; juntar durante 18 anos 908 fascículos dominicais do Suplemento Literário do Estado de S. Paulo e encadernar cada ano um volume é trabalho de paciência” (DOYLE, 1999, p. 63).

Felizmente para nós, não faltaram paciência, persistência, zelo e generosidade a esses dois homens, dispostos a compartilhar com seus contemporâneos e pósteros os admiráveis acervos que formaram ao longo de suas vidas. Para concluir, resta destacar que a mesma generosidade marcou o relacionamento entre eles, que, se às vezes disputavam a aquisição de um mesmo livro raro, nem por isso se esqueciam da sólida amizade e da mútua admiração que os uniam, como bem mostra o trecho reproduzido abaixo:

O sonho de um colecionador era, e será sempre, possuir um exemplar da primeira edição de A moreninha, de Joaquim Manoel de Macedo, de 1844, e de que se conhecem apenas dois exemplares, um deles pertencente ao dr. Mindlin. Bem, quando, em 1984, foi leiloado um exemplar da primeira edição de Iracema, de José de Alencar, dr. Mindlin arrematou o livro, embora Plínio Doyle também o desejasse. Dias depois, o primeiro, em visita ao sabadoyle, lamentou a derrota do anfitrião na aquisição da obra e, atribuindo-lhe "maior amor ao vil metal do que à virgem dos lábios de mel", partiu de volta a São Paulo, onde mora. Passados alguns dias, Plínio Doyle recebeu — imagina-se com que encantamento -, o precioso exemplar, com a seguinte dedicatória: "Transferido com muita alegria ao querido Plínio." E num cartãozinho, dentro do livro, o orgulho saudável do bibliófilo-amigo, na bem-humorada referência à obra de Macedo: "Aí vai a moreninha Iracema." (BEZERRA, 2006).

\section{REFERÊNCIAS}

A BIBLIOTECA Mindlin na USP. Disponível em: <http://www.bbm.usp.br/node/1 > Acesso em: 20 ago. 2014.

BEZERRA, Elvia. Plínio Doyle: patriarca em flor. Disponível em: <http://www.artefatocultural.com. br/ArtigosEdo3_Elvia.htm>. Acesso em: 20 ago. 2014.

COLEÇÃO Plínio Doyle. Disponível em: <http://www.casaruibarbosa.gov.br/interna.php?ID $\mathrm{S}=23 \& \mathrm{ID} \_\mathrm{M}=309>$. Acesso em: 20 ago. 2014.

DOYLE, Plínio. Uma vida. Rio de Janeiro: Casa da Palavra; Fundação Casa de Rui Barbosa, 1999. 
JOSÉ e Guita Mindlin. Disponível em: <http://www.bbm.usp.br/node/53>. Acesso em: 20 ago. 2014. JOSÉ Mindlin - Biografia. Disponível em: <http://www.academia.org.br/academicos/josemindlin/biografia $>$. Acesso em: 20 ago. 2014.

MINDLIN, José. Uma vida entre livros: reencontros com o tempo. São Paulo: Edusp; Companhia das Letras, 1997.

SENNA, Homero. O Sabadoyle: histórias de uma confraria literária. Rio de Janeiro: Casa da Palavra, 2000.

\section{SOBRE A AUTORA}

Cássia dos Santos é bacharel e licenciada em Letras e Doutora em Teoria e História Literária pela Universidade Estadual de Campinas (UNICAMP). Integra o corpo docente da Pontifícia Universidade Católica de Campinas, estando vinculada à Faculdade de Letras.

E-mail:cassia23@gmail.com

Recebido em 30 de agosto de 2014 e aprovado em 02 de abril de 2015. 